\title{
Operation And Maintenance In Facilities Management Practices: A Gap Analysis In Malaysia
}

\author{
Zuraihana Ahmad Zawawi ${ }^{1 a}$, Mohd Khazli Aswad Khalid ${ }^{1}$, Nur Azfahani Ahmad ${ }^{1}$, Nurul Fadzila Zahari ${ }^{1}$ and Nuzaihan Aras \\ Agus Salim² \\ ${ }^{1}$ Faculty of Architecture, Planning \& Surveying, University Teknologi MARA Seri Iskandar Campus, 32610 Bandar Seri Iskandar, Perak, \\ Malaysia \\ ${ }^{2}$ School of Housing, Building and Planning, Universiti Sains Malaysia, 11800 USM, Pulau Pinang, Malaysia
}

\begin{abstract}
Facilities management in Malaysia has started as early as 1990s during the development of mega projects such as Putrajaya in 1999 [8, 9]. During this period, Malaysia was introduced to an integrated property management and maintenance services known as facilities management. However, its implementation according to the standard practice is still being disputed. The purpose of facilities management standard practices is to provide the facility management profession with a leading reference on facilities management activities and standards. Therefore, the determination of how far the gap in FM current practice is essential to help our FM industry. Thus, the aim of this study is to establish the gap between the current practices and the standard practices and also how far the gap should be satisfied. A set of questionnaire was designed upon literature and previous research done to gather the required information. The study is subjected to FM organizations in private sectors and only the personnel at management level are assessed. There were certified that most of the practices that assessed by means of gap analysis had an acceptable result which the gap between the current practices and the standard practices are not too far.
\end{abstract}

\section{Introduction}

Facilities Management is performed during the operational phase of a building's life cycle, which normally extends over many decades $[8,9]$. As such, it will represent a continuous process of service provision to support the owner's core business and one where improvement will be sought on a continuous basis. It is essential that decision-making in the preceding design and construction phases before is therefore properly informed about operational requirements if he facility is to provide optimal support to the owner's business. In this connection, facilities management can be seen as an integral part of a coordinated and controlled process of design, engineering, construction and operations.

There is no general approach to manage facilities. Each organization, even within the same sector will have different needs. Understanding those needs is the key to effective facilities management measured in terms of providing best value.

\subsection{Problem statement}

The purpose of facilities management standard practices is to provide the facility management profession with a leading reference on facilities management activities and standards. Most of FM industry players were unaware about the importance to implement the practices which should follow the standard, to ensure it will be successfully delivered to the user. Therefore, it is important by the FM industry player to overlook at the current state of practice before developing robust strategies in order to manage facilities efficiently and effectively, within the context of the organization's strategic business plan.

\subsection{Research aim and objective}

The objective of this study is to determine the gap in the current stages of operation and maintenance in facilities management practice to be the base of a strategic plan that can be applied in the Malaysia FM industry.

\subsection{Scope of study}

The extent of this study is subjected to FM organizations in private sectors and only the personnel management level is assessed. The respondents are only limited to those within peripheral of Klang Valley where most numbers of FM service providers in Malaysia could be identified. There are 41 numbers of respondents identified and assessed which represent about $56 \%$ of the sample population.

\section{Literature review}

\footnotetext{
${ }^{a}$ Corresponding author: zuraihana@perak.uitm.edu.my
} 
There are several references used as the research literature in order to have better knowledge prior to this study. The literature review will be discussed about gap analysis and emphasis on building operation and maintenance in facilities management practices.

\subsection{Gap analysis}

Gap analysis generally refers to the activity of studying the differences between standards and the delivery of those standards (Encyclopedia of Management, 2009). In business and economics, gap analysis is a tool that helps a company to compare its actual performance with its potential performance. It refers to an analysis of the distance between where you are today versus where you need to be in order to meet the standard requirements. Once the gap is determined, a strategic plan can be developed that will move the organization from its current state towards its desired future state.

The other purposes of a gap analysis as suggested by [13] are:

- Identify gaps between the current management systems and the standard practice

- Collect policies, procedures, programs, and personnel that support the current practice

- Establish a list of actions to achieve conformance with the standard

In this study, the differences between standard theoretical practice and actual practices in the delivery of facilities management industry will be determined and discussed. The differences could be used to explain the achievement and to document the areas which need improvement.

\subsection{Building operation and maintenance practice}

Facilities management involves all types of building elements, including façade, floors, air-conditioning, electrical, utilities and everything which attached to the building. Facilities management also involves monitoring the consumption rate of utilities and giving effort to save a little on it.

Facilities management is important to make sure that a company is in top shape for an operation. A lot of information can be derived from conducting a facilities management check. The results of the review are then discussed with the person who has a high authority in the organization to come with some suggestions that can help the business operate better.

[1] explained that the operation and maintenance (O\&M) include all aspects of running a building over the course of its useful life. One goal of effective O\&M is to achieve the intent of the original building design team, so that building systems deliver services to building occupants.

The proactive operation and maintenance can yield benefits such as reduced solid and hazardous waste generation, less hazardous air pollution, extended service life of equipment and building materials, better indoor air quality, and fewer occupant complaints [6].

\subsection{Building maintenance management}

British Standard Glossary of terms (3811:1993) defined maintenance as 'the combination of all technical and administrative actions, including supervision actions, intended to retain an item in, or restore it, to a state in which it can perform a required function. In addition, maintenance is a set of organized activities that are carried out in order to keep an item in its best operational condition with minimum cost acquired.

\subsubsection{Maintenance activities}

Activities of maintenance could be either repair or replacement activities, which are necessary for an item to reach its acceptable productivity condition or these activities, should be carried out with minimum possible costs.

Table 1: Types of maintenance suggested by various authors

\begin{tabular}{|l|l|l|l|l|}
\hline \multicolumn{1}{|r|}{ Author } & $\begin{array}{l}\text { Fitch, } \\
\mathbf{1 9 9 2}\end{array}$ & $\begin{array}{l}\text { Sievert, } \\
\mathbf{2 0 0 1} \\
\text { Mypes of } \\
\text { Maintenance }\end{array}$ & $\begin{array}{l}\text { Mobley, } \\
\text { et. al., } \\
\mathbf{2 0 0 6}\end{array}$ & $\begin{array}{l}\text { This } \\
\text { Study, } \\
\mathbf{2 0 1 6}\end{array}$ \\
\hline Predictive & $\sqrt{ }$ & $\sqrt{ }$ & $\sqrt{ }$ & $\sqrt{ }$ \\
\hline Preventive & $\sqrt{ }$ & $\sqrt{ }$ & $\sqrt{ }$ & $\sqrt{ }$ \\
\hline Proactive & $\sqrt{ }$ & $\sqrt{ }$ & & \\
\hline Reactive & & & & \\
\hline Planned & & & & $\sqrt{ }$ \\
\hline Program & & & $\sqrt{ }$ \\
\hline Improvement & $\sqrt{ }$ & & $\sqrt{ }$ & \\
\hline Corrective & & & $\sqrt{ }$ \\
\hline Breakdown & $\sqrt{ }$ & & & \\
\hline $\begin{array}{l}\text { Breakdown } \\
\text { emergency }\end{array}$ & & $\sqrt{ }$ & & \\
\hline
\end{tabular}

Table 1 shows numbers of maintenance routine which suggested by various authors. However, only five types of maintenance routines were chosen in this study. Those maintenance routines were chosen as it illustrates many other types of maintenance. The approach towards maintenance should include some of the following maintenance routines because these are the tools that are widely used in facilities management.

\section{i. $\quad$ Predictive maintenance}

- Predictive maintenance is the technique used to check the condition of the different equipment used

- During the evaluation, several things are checked to make an estimate when equipment maintenance should be scheduled

ii. Preventive maintenance

- Includes activities that are performed routinely at planned time intervals on specific systems, equipment or components in order to avoid total failure 
iii. Improvement maintenance

- Improvement maintenance allows equipment to be improved its performance at times that do not interfere with production schedules, thereby removing one of the largest factors from downtime cost.

- Improvement maintenance sometimes known as Condition Based Maintenance which aims to reduce or eliminate the risk of failure in future

iv. Corrective maintenance

- Corrective maintenance activities are generated from preventive maintenance inspections, routine operational requests, and routine service requirements. These activities make up the maintenance backlog and should be planned and scheduled in advance. This approach is the most cost effective way to performed maintenance.

$v$. Breakdown or emergency maintenance

- In many situations, equipment is run until it breaks down. Thus, the technician will only react on equipment that is malfunctioning.

- Breakdown or emergency maintenance also known as run-to-failure or remedial maintenance, is an activity performed on a nonroutine basis and is reconstructive in nature

- This approach is the most expensive way to coordinate maintenance

\subsubsection{Maintenance policy}

The maintenance policy is a document which provides a maintenance management framework to ensure the facilities are maintained effectively to support the strategic objectives of operation and maintenance. The purpose of maintenance policy is to outline the roles and responsibilities of O\&M team and sometimes define funding allocation responsibilities to achieve effective maintenance of facilities.

\subsubsection{Maintenance schedule}

Maintenance schedule defined as a schedule of the frequency of the required or recommended maintenance, testing or inspection for each type of equipment [1]. The schedule may include daily, weekly, monthly and yearly attendance times.

The maintenance schedule may be in separate tables for each type of equipment, or facilities.

\subsubsection{Maintenance reports}

Many reports can be developed to aid in measuring and controlling maintenance activities. This may include complete job reports, backlog reports, labor utilization reports, overtime reports, and jobs in progress [14].

- Complete job reports - show the actual versus estimated performance in terms of cost and time. Large variances can mean poor performance, poor accounting for charges, poor estimating, or poor planning
- Backlog reports - show the amount of work remaining at any point in time. These reports identify whether the organization is current, ahead or behind schedule, and can help determine if the maintenance department is under- or overstaffed. The backlog report can also be used to prioritize maintenance jobs by equipment or area

- Overtime report - shows the number of hours spent for premium time as a percentage of total work-hours. Overtime reports also indicate undesirable levels of breakdown maintenance

- Labor utilization report - breaks the maintenance payroll hours down into dollars (Ringgit). The report can be prepared from the daily time sheets filled out by each employee or contractor

All of these information or documents should be incorporated into an annual operating budget. It is important to determine what percentage of maintenance time is actually productive. Direct and indirect costs should be evaluated.

\subsubsection{Emergency response plans}

The emergency response plans are made with the purpose to reduce the possibility of injury to personnel and damage to the facility in an event of an emergency.

The emergency response plans, however, should be carried out in accordance with the regulations and guidelines from the authority and assigned emergency team.

In the U.S, one standard which could be used in emergency management is the Facility Management Standard for Facilities, Infrastructure and Environment (FMSFIE) that was developed by the U.S. Army Corps of Engineers.

The emergency response plans should detail what the response team must do in case of an emergency. Among the type of response plan which widely used are the Building Emergency Plan and Evacuation Plan.

\subsection{Operation and maintenance manual}

A building which designed with the control systems that can achieve high levels of energy efficiency should be managed accordingly to ensure it performs as required. The standard operation and maintenance manual are among the essential tools which aid in operation and maintenance management.

The Operation and Maintenance (O\&M) Manual is an important tool in ensuring the effective and energy efficient functioning of the building. A basic outline of such a document is suggested [6].

Ideally the outline of the O\&M manual should be prepared at an early stage of the design, and updated as the project develops. In this way, the team will ensure that O\&M considerations are addressed at each stage of the design.

The contents of the O\&M manual will vary between different buildings, depending on the systems that are included in the buildings. 
Maintenance requirements may vary depending on the materials, components and systems that are included in the building. The implications of departments from the ideal maintenance program may also vary, depending on the resilience of the different elements of the building.

\subsection{Standard operating procedure (SOP)}

The standard operating procedure is a written procedure prescribed for repetitive use as a practice, in accordance with agreed upon specifications aimed at obtaining a desired outcome. An important aspect of a quality system is to work according to unambiguous Standard Operating Procedure (SOP).

The purpose of an SOP is to carry out the operations correctly and always in the same manner. An SOP should be available at the place where the work is done.

An SOP is a compulsory instruction. If deviations from the instruction are allowed, the conditions for that should be documented, including who can give permission for that and what exactly the complete procedure will be.

\subsection{Performance measurement}

The need of performance measurement in facilities management is to have guidance in decision making by the management $[2,3]$.

The traditional view of performance measurement which determined by [7], has three broad purposes, which are:

- To ensure the achievement of goals and objectives

- To evaluate, control and improve procedures and processes

- To compare and assess the performance of different organizations, terms and individual

In addition, [2, 3] described performance measurement as a process of assessing progress towards achieving pre-determined goals and including the following:

- Information on the efficiency by which resources are transformed into goods and services

- The quality of these outputs and outcomes

- The effectiveness of organizational objectives

However, [5] emphasize the need to measure performance gaps between service delivery and customer satisfaction thus suggested the application of a management by variance tool. The tool identifies business and facility key performance indicators (KPI), helping to create a rank order among the benchmarking criteria.

\subsubsection{Key performance indicator}

The key performance indicators for the maintenance organization may include key performance indicators for other areas of accountability, such as health and safety performance, employee performance management, training and development, response time, etc. [10].
Key performance indicators for the maintenance function need to include both leading (maintenance process) measures and lagging (result) measures.

\section{Methodology}

The study was conducted in order to determine whether there have gaps in the current state of operation and maintenance management in Facilities Management (FM) practices and the standard practice which applied throughout the world. In order to achieve the objectives, the author adopts some methods for this study. Secondary data gathered in literature review used as the basis in developing a questionnaire. The data gathered from the questionnaire were then computed for interpretation as primary data. Along with primary data, the author also made some use of secondary data which has been gathered to support the survey results.

\subsection{Conducting a gap analysis}

Before a gap analysis has been undertaken, the analyst must be familiar with; in this case, Facilities Management framework and several days must allow in completing data collection.

Steps in a gap analysis:

i. Facility walk-through

- Identify activities, products and services

- Support activities

- Develop a comprehensive picture of the facility

- Maps, pictures and lists of tenants and departments

ii. Document review

- Policy statements

- Mission statements

- SOPs

- Position descriptions

- Other related documents

iii. Staff interviews

- Identify organizational structure

- Identify requirements to fulfil mission

- Determine awareness and knowledge level of staffs

iv. Identify and document gaps

- Compare with standard practice

- Make a list of specific actions to close gaps

\subsection{Measuring the gap}

To measure the gap, author computed the data by using Likert system, suggested by [11] to determine the state of current practice based on mean index that has been calculated early as follows:

$\begin{array}{rll}\text { i. } & \text { Strongly Agree } & =1.00<\text { mean index }<1.50 \\ \text { ii. } & \text { Agree } & =1.50<\text { mean index }<2.50 \\ \text { iii. } & \text { Neutral } & =2.50<\text { mean index }<3.50 \\ \text { iv. } & \text { Disagree } & =3.50<\text { mean index }<4.50 \\ \text { v. } & \text { Strongly Disagree } & =4.50<\text { mean index }<5.00\end{array}$


In order to use the Likert-scale for interpretation, weighted mean to represent each question was computed. Weighted mean is the average wherein every quantity to be averages has a corresponding weight. These weights represent the significance of each quantity to the average. To compute for the weighted mean, each value must be multiplied by its weight. Products should then be added to obtain the total value. The total weight should also be computed by adding all the weights. The total value is then divided by the total weight [11].

In conjunction with the use of the Likert-scale system, the author has adjusted the choices of frequency towards the questions in questionnaire as follows:

i. Practice Most - organization is familiar with the matter and practice it most of the time

ii. Practice Seldom - organization is familiar with the matter and practice it seldom

iii. Practice Once - organization practice the matter just once

iv. Aware (but not practice yet) - the organization has knowledge about the matter, but just not practice yet

v. Unaware (never practice) - organization unaware about the matter, thus never practice it

\section{Findings and discussion}

For establishing the gap, the classification of scale index, which adopted from [11] has determined as follows:
i. Good $=1.00<$ mean index $<1.50$
ii. Acceptable $=1.50<$ mean index $<2.50$
iii. Average $=2.50<$ mean index $<3.50$
iv. $\mathrm{Bad}=3.50<$ mean index $<4.50$
v. Poor $=4.50<$ mean index $<5.00$

The summary of the frequency scale for all items and its classification by using the Likert Scale system explained in Table 2.

Table 2: The summary of the scale for all categories and its classification by using Likert Scale

\begin{tabular}{|c|c|c|c|}
\hline \multirow{2}{*}{ Categories } & Type & \multicolumn{2}{|c|}{ Likert Scale } \\
\cline { 3 - 4 } & $\begin{array}{c}\text { Mean } \\
\text { Index }\end{array}$ & Classification \\
\hline $\begin{array}{c}\text { Undertake } \\
\text { Maintenance } \\
\text { Routine }\end{array}$ & $\begin{array}{c}\text { Predictive } \\
\text { maintenance }\end{array}$ & 1.83 & Acceptable \\
\cline { 2 - 4 } & $\begin{array}{c}\text { Preventive } \\
\text { maintenance }\end{array}$ & 1.39 & Good \\
\cline { 2 - 4 } & $\begin{array}{c}\text { Improvement } \\
\text { maintenance }\end{array}$ & 2.66 & Average \\
\cline { 2 - 4 } & $\begin{array}{c}\text { Corrective } \\
\text { maintenance }\end{array}$ & 2.00 & Acceptable \\
\cline { 2 - 4 } & $\begin{array}{c}\text { Breakdown } \\
\text { or } \\
\text { Emergency }\end{array}$ & 1.85 & Acceptable \\
\hline
\end{tabular}

\begin{tabular}{|c|c|c|c|}
\hline \multirow{3}{*}{ Categories } & \multirow[b]{2}{*}{ Type } & \multicolumn{2}{|c|}{ Likert Scale } \\
\hline & & $\begin{array}{l}\text { Mean } \\
\text { Index }\end{array}$ & Classification \\
\hline & maintenance & & \\
\hline \multirow{4}{*}{$\begin{array}{c}\text { Preparing } \\
\text { Maintenance } \\
\text { Report }\end{array}$} & $\begin{array}{c}\text { Complete } \\
\text { Job Reports }\end{array}$ & 1.66 & Acceptable \\
\hline & $\begin{array}{l}\text { Backlog } \\
\text { Reports }\end{array}$ & 1.88 & Acceptable \\
\hline & $\begin{array}{l}\text { Overtime } \\
\text { Reports }\end{array}$ & 1.51 & Acceptable \\
\hline & $\begin{array}{c}\text { Labor } \\
\text { Utilization } \\
\text { Reports }\end{array}$ & 2.68 & Average \\
\hline \multirow[t]{4}{*}{$\begin{array}{c}\text { Referring } \\
\text { O\&M Tools }\end{array}$} & $\begin{array}{c}\text { Maintenance } \\
\text { Manual }\end{array}$ & 1.59 & Acceptable \\
\hline & $\begin{array}{c}\text { Standard } \\
\text { Operating } \\
\text { Procedure }\end{array}$ & 1.68 & Acceptable \\
\hline & $\begin{array}{l}\text { Maintenance } \\
\text { Policy }\end{array}$ & 1.78 & Acceptable \\
\hline & $\begin{array}{c}\text { Maintenance } \\
\text { Schedule }\end{array}$ & 1.20 & Good \\
\hline \multirow{3}{*}{$\begin{array}{c}\text { Emergency } \\
\text { Response Plan } \\
\text { Testing }\end{array}$} & Building & & \\
\hline & $\begin{array}{c}\text { Emergency } \\
\text { Plan }\end{array}$ & 2.10 & Acceptable \\
\hline & $\begin{array}{c}\text { Evacuation } \\
\text { Plan }\end{array}$ & 2.61 & Average \\
\hline $\begin{array}{c}\text { Undertake } \\
\text { Performance } \\
\text { Measure }\end{array}$ & $\begin{array}{c}\text { Performance } \\
\text { Measure } \\
\text { (KPI, etc.) }\end{array}$ & 1.88 & Acceptable \\
\hline
\end{tabular}

By referring Table 2, the explanation can be found by category as follows:

i. Undertake maintenance routine - most of the maintenance routines are at an acceptable level. Only preventive maintenance satisfied the standard which it is at a good level. However, the improvement maintenance is quite far from the standard which it is at an average level.

ii. Preparing maintenance report - most of the maintenance reports are prepared at acceptable level. Only labor utilization report prepared at average level.

iii. Referring O\&M tools - most of the O\&M tools are being referred at acceptable level. However, the maintenance schedule satisfied the standard which it is being referred at good level.

iv. Emergency response plan testing - building emergency plan being tested at an acceptable level while evacuation plan only being tested at an average level.

v. Undertake performance measure - the performance measure is undertaken at the acceptable level. 


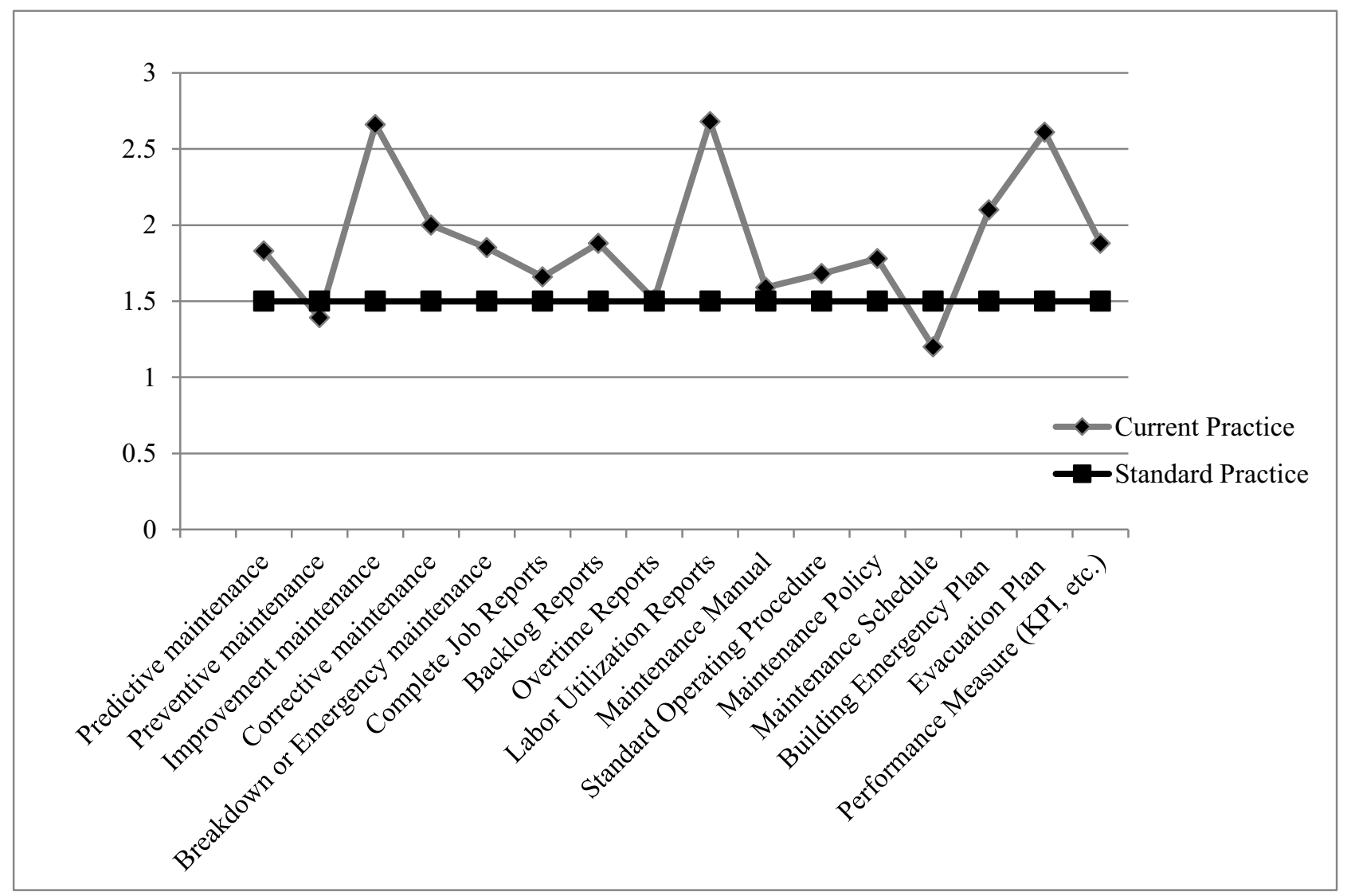

Figure 1: The gap analysis chart shows the state between current practice and standard practice

To get a clearer view about the gap which has been established by the analysis, Figure 1 shows the clear picture of the gap between current practice and standard practice. The standard practice has set at the least number in good scale (1.5) which only two items (preventive maintenance and maintenance schedule) achieved the level of standard practice. Most of the items tested were at an acceptable level. The other three items (improvement maintenance, labor utilization reports and evacuation plan) had a gap which is quite far from standard practice level.

The preventive maintenance relatively satisfied the standard practice because this type of maintenance routine is the crucial item in any maintenance program. However, the improvement maintenance may be somewhat unusual for the O\&M practice or this type of maintenance may rather known as other name and this type of maintenance actually covers the other which similar nature of activities. However, the corrective maintenance may be at that level due to the nature of its routine which undertake only when the equipment failed to operate.

Since almost of the reports are prepared at acceptable level, the upper level management should be aware of this situation which the neglected in preparing those reports will result in the lost of important data that may be basis in future decision-making.
The labor utilization report, for example, is very important in determining of the manpower supplies which, with that information, the upper level management can assign the labor sufficiently.

All of those O\&M tools are likely to practice excellently. As noted, the gaps between the current practices and the standard practices are just close. It is certified that the O\&M team realized the fact that O\&M tools should be referred frequently in order to ensure that every activity are delivered efficiently.

The gaps between the standard practices and current practices in both emergency response plan category also likely to be far. This circumstance might be caused by the testing schedule which had stated as that means.

The gap in performance measure is seen quite close, which is declared that the respondents are conscious of how important to carry out performance measure.

In summary, it is evidenced that most of respondents exercising sufficient level in the most O\&M practices which include carrying out the various types of maintenance activities, preparing various types of maintenance reports, and also make use various types of O\&M tools. As well as practicing the O\&M at satisfying level, the majority of respondents also have set up the key performance indicator as the performance measurement in their organizations.

\section{Conclusion and recommendation}

Most of the practices that assessed by means of gap analysis had an acceptable result which the gap between 
the current practices and the standard practices are not too far. Consequently, if the organization wants to implement the change in their O\&M practices, the gaps established should be bridged. The gaps can be brought nearer with continuous learning effort. The effort will be easier if the FM key player is more understanding the actual concept of facilities management.

The gap analysis of operation and maintenance management provide a clear indication of compliance to the standard practice. They indicate where to take specific action because of a gap in the way maintenance is being performed. This gap in the execution of the maintenance will eventually lead to asset failure and some effort should be undertaken to ensure that the industry will be more recognized.

Gap analysis is a good way to jump start the business practices and also helps create a list of actions for the management team. Gap analysis utilizes comparative analysis techniques to identify the differences that exist between the current stages and the desired level. It is essential to identify the nature of the current process in order to make this comparison.

Effective use of gap analysis can effectively minimize risks and reduce the costs of the change management effort.

In summary, an organization's success depends largely on the way in which the various facilities are managed, and this is why many businesses are now making use of facilities management organizations.

\section{References}

1. BSI (2007) BS EN 15221-1:2006 (E). BSI.

2. C.C. Bobenhousen. Viridian Energy \& Environmental, Inc. (2009)

3. D. Amaratunga \& D. Baldry. Proceedings of Int. Postgrad. Conf., pp.193-202 (2002)

4. D. Amaratunga \& D. Baldry. J.FM, 6, 5-22, (2008)

5. E.C. Fitch. Elsevier Science Publishers Ltd, England, (1992)

6. J. Hinks, P. Mcnay. Facilities, 17, 31-53, (1999).

7. J.H.K. Lai, F.W.H. Yik, P. Jones. HK Polytechnic Univ., China and Cardiff Univ, UK (2005)

8. J. Teague, S. Eilon. Appl. Economics, Vol. 5, 99. 133-145. (1973)

9. M. Noor, M. Pitt. J. FM (2008)

10. M. Noor, M. Pitt. Facilities, 27, 211-228. (2009)

11. M. Sondalini. http://www.lifetime-reliability.com, (2008)

12. R. Likert. Archives of Psychology, No.140 (1932)

13. T.M. Linda, K. Non. J. FM, Vol. 4 Iss:4, pp. 234244, (2006)

14. W. Isobel. eHow Contributor. (2010)

15. W.R., Sievert. R.S. Means Company, Inc. (2001 